\title{
Predicting the effects of capping contaminated sediments via numerical simulations
}

\author{
I. Bortone $\mathrm{a}^{\mathrm{a}^{*}}$, M. Di Natale ${ }^{\mathrm{b}}$, D. Musmarra ${ }^{\mathrm{b}}$
}

a School of Water, Energy and Environment, Cranfield University, College Road, Cranfield, United Kingdom. imma.bortone@cranfield.ac.uk

bDipartimento di Ingegneria, Università degli Studi della Campania “L. Vanvitelli”, Via Roma 9, 81031, Aversa

(CE), Italy. michele.dinatale@unicampania.it; dino.musmarra@unicampania.it

\begin{abstract}
Contaminated sediments are one of the key risks to human health and the environment, due to high concentrations of many types of substances contained in them and their direct contact with the aquatic fauna. This contributes to fish consumption advisories and limits the uses of many water bodies. In the present study, an in-situ sediment capping (ISC) is considered as a potential remedy to minimise the exposure of aquatic ecosystems to sediment contaminants and a valid alternative to ex-situ remediation options, by reducing contaminant fluxes to the upper water. Numerical design simulations, taking into account a biosorptive sediment cap and comparing different adsorptive characteristics of sediments, are proposed. As a case study, PCBs contaminated sediments of Lake Hartwell, an artificial lake located in South Carolina, USA, were considered. A numerical predictive model of concentrations in a multi-layered bed sediment and overlying water was developed in order to evaluate the long term effectiveness of ISC of different thicknesses. Results showed that, for the case study, a minimum $20 \mathrm{~cm}$ cap allows to reduce the contaminant flux to the overlying water through reaction of the contaminants with the capping matrix, by highlighting how sediment biosorptive characteristics can influence the cap design.
\end{abstract}

Keywords: sediment capping, contaminated sediments, contaminant transport, reactive transport, flow modelling

\footnotetext{
*Corresponding author: Imma Bortone, School of Water, Energy and Environment, Cranfield University, College Road, Cranfield, United Kingdom. Tel.: +44 01234 754819. E-mail address:

imma.bortone@cranfield.ac.uk
}

\section{Introduction}

For several centuries industrial activities and urban development have released various types of contaminants into the environment. A large portion of these have reached the aquatic environment through river transport and direct runoff. As a consequence, most sediments contain high concentrations of environmental pollutants and toxins, representing a serious threat to aquatic fauna and human health, via the food chain $[1,2]$. Pollutants affect individual 
organisms and ecosystems as a whole through biomagnification and bioaccumulation, damaging the biodiversity. Many benthic and epibenthic organisms, which represent most of the lower tropic levels, are directly exposed to these substances [3, 4].

The fate and behaviour of contaminants into sediments is controlled by a combination of physical, chemical and biological factors [5,6], which cause the diffusion of these into the upper water. While quantitative assessment of the immediate ecological effects of contaminated sediments is a contentious issue, the risks related to the contamination resuspension over time are even more difficult to assess [7]. Remediation of contaminated sediments has consequently become an important scientific and public concern all over the world [4].

There are several ex-situ remediation strategies to treat contaminated sediments, but all require dredging of the contaminated sediment and a successive transport of masses to the treatment plants $[8,9]$. Often, the problems connected to the release of contaminants during dredging, the high cost of moving sediments and the difficulty in finding available space to construct confined disposal facilities, reduce the applicability of these techniques. On the contrary, insitu options offer the advantage of reducing the costs and material losses associated with the excavation and relocation of sediments, and are less invasive [8, 10].

This study examines in-situ capping (ISC) of contaminated sediments. ISC consists of layering clean/reactive material of a designed thickness over the contaminated sediments to minimise the exposure of aquatic ecosystems to contamination [10].

ISC acts like a horizontal reactive permeable barrier, whose technology has demonstrated to be effective for many types of contaminants [11-13]. Specifically, ISC physically separates, chemically isolates and precludes direct contact of both the benthic diffusive boundary layer and the bioturbation layer (biologically-active zone at the water-sediment interface, where biological activities occur) with the contaminated sediments. In addition, it prevents mobilization and transport of contamination and provides new benthic habitat for the biological community [10].

Contaminant flux can be reduced through sorption of contaminants in the sediment cap matrix and by increasing the resistance to contaminant diffusive transport $[6,10]$.

ISC has shown to be technically feasible in field and laboratory tests $[14,15]$, although geochemical and reactive transport models have been proposed in last years, to extrapolate contaminant breakthrough results to long timescales and simulate the cap integrity over the time $[16,17]$. Most of models focus on describing physical processes such as advection, dispersion, consolidation, and bioturbation, simplifying geochemical and biogeochemical processes [18, 19]. Recently, more detailed models have been tested by representing partitioning and fate of contaminant via a set of integrated equilibrium and kinetic chemical reactions [20];

ISC efficiency is based on designing the right thickness after the identification of the most suitable cap material, with particular attention to its sorption capacity [6].

Depending on the magnitude and type of polluted fluxes, advanced and/or multi layered ISC have been suggested. These added mineral and organic substrates for adsorption [21], and/or promoted geochemical conditions for precipitation (or co-precipitation) in case of metals [22]. In addition, active biological treatments within the cap have been proposed to help stimulating biotransformation within the cap matrix. As contaminants migrate through the cap, 
biotransformation significantly delay and reduce contaminant breakthrough to the bioturbation layer at the cap-water interface, and also allow potential cap placement at locations where enhanced solute advective flow compromises traditional cap performance [5].

In presence of organic compounds, studies of sorption in sediments have revealed that the natural organic matter in the sediments is mainly responsible for the accumulation onto sediments and soils [23]. Schwarzenbach et al. [24] reported that even in sands with low organic carbon content, some sorption onto mineral surfaces can occur, with an effective lowerbound equivalent to an organic carbon content of 0.01-0.1\%. Consequently, such interaction should be considered when assessing caps [6].

In relation to that, this study proposes to examine a multi-layered sediment capping system for contaminated sediments via numerical modelling, where a biodegradative/sorptive pollutant transport throughout bed sediments and interactions with benthic fauna were taken into account. The objective is to find the optimal cap thickness, reducing the contaminant flux to the upper water for PCBs contaminated sediments in Lake Hartwell: an artificial lake located in the north-west region of South Carolina, considered as a case study [25, 26]. Site specific biodegradation and different organic carbon fractions of the sediment cap were included in the model. Fate and transport of PCBs within the sediment cap system were simulated by using COMSOL Multiphysics, a numerical predictive finite element model. The multi-layered biogeochemical reactive system allowed an evaluation of the ISC long term effectiveness and a comparison of different case scenarios was developed.

\section{MATERIALS AND METHODS}

\subsection{Sediment cap conceptual and mathematical model}

Aquatic sediments, suspended or settled to the bed, act initially as sinks, and ultimately as sources, for contaminants released from a variety of natural and anthropogenic activities [2]. The fate and transport of these contaminated sediments generally define the overall pattern of chemical contaminant distribution within the aquatic ecosystem. Processes governing transport of pollutants into bed sediments, include contaminant diffusion through pore water and transport of dissolved contaminants by advection, physical, chemical and biological reactions, and sediment mixing as a result of biological activities and periodic events at the benthic layer (i.e., surficial layer at the sediment-water interface) [5, 6] as shown in Fig.1.

The main goals of a cap design are to ensure that:

- subaqueous processes do not erode and re-suspend the underlying contaminated sediments over the time,

- to maintain its reactive properties over time, and

- to guarantee that it efficiently reacts with all types of contaminants present on site, while simultaneously preserving benthic organisms. For these purposes, 'ad hoc' and tested capping materials can be combined [27-30]. 


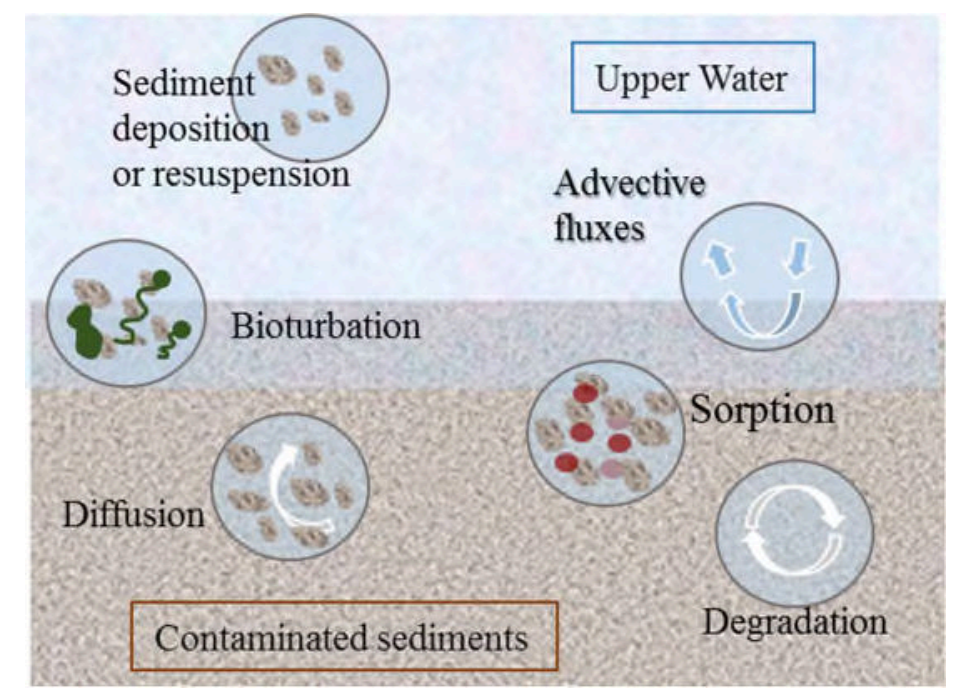

Fig 1. Fate and transport processes of contamination into sediments

The total thickness of an ISC and the materials used is determined through the evaluation of all the pertinent processes involved and on the correct modelling design of the intervention. Fundamental engineering design criteria for an effective sediment cap embrace the construction of a conceptual model, containing the relevant medium properties, the transport processes taking place in the different layers, the extension and type of contamination (e.g. vertical substances distribution profiles etc.), the main cap characteristics (e.g. thickness, type of material, etc.), and the mechanisms which govern the capture/transformation of the target pollutant. A sand cap can be modelled as a system of three/four layers, as shown in Fig.2 [10, 19]. These include the overlying water column, the sediment cap, $h_{\text {cap }}$, which is further divided into a biologically active layer also known as the bioturbation layer, with a depth of $h_{\text {bio }}$ and the contaminated sediment bed, $h_{\text {sed }}$. At the sediment-water interface, the magnitude of the contaminant flux is set by the benthic boundary layer mass transfer coefficient $\left(k_{b l}\right)$ [19].

The effectiveness of the intervention can be determined by predicting the contaminant flux at the cap surface with the substances breakthrough time [6].

As transport processes and concentration gradients into sediments are predominantly vertical, a numerical one-dimensional model can be considered to simulate the distribution of chemical species in pore water systems [31]. 


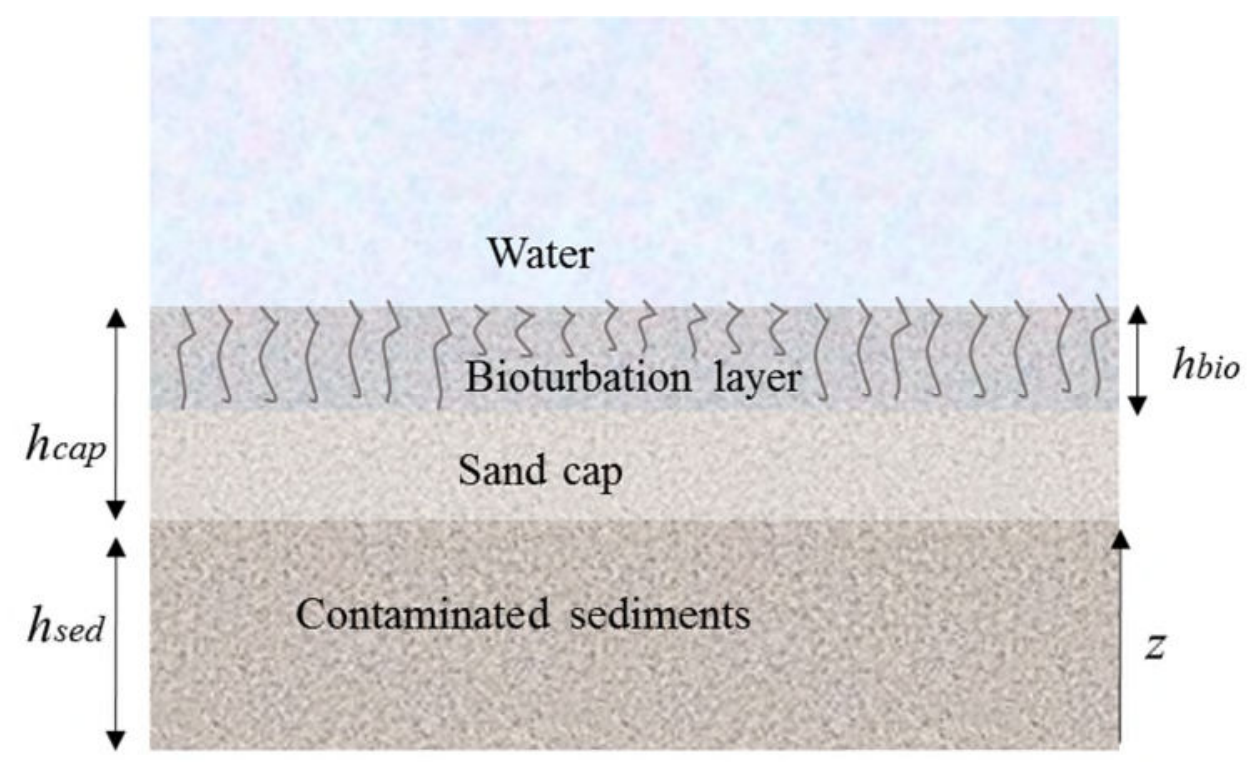

Fig 2. In-Situ sediment Capping (ISC) design model.

The governing equation for one-dimensional transport describing the vertical transport of a contaminant, $C$, over the time, $t$, with linear sorption and overall first-order contaminant degradation, through a homogeneous sediment layer, $h$, can be written as in the following [19, 32]:

$R_{f} \frac{\partial C}{\partial t}=D_{e f f} \frac{\partial^{2} C}{\partial z^{2}} \mp w \frac{\partial C}{\partial z}-R_{f} \lambda_{r} C$

where $C$ is the porewater concentration $(\mu \mathrm{g} / \mathrm{L}), w$ is the groundwater seepage Darcy velocity $(\mathrm{m} / \mathrm{s})$ or the velocity of burial of particles below the sediment-water interface (i.e., sediment burial rate) when considered with positive sign. $\lambda_{r}(1 / \mathrm{s})$ is the degradation constant of contaminant in both solid and aqueous phase while $D_{\text {eff }}\left(\mathrm{cm}^{2} / \mathrm{s}\right)$ is $t$ the effective hydrodynamic dispersion coefficient [17]. The terms of right side of Eq.(1) represent respectively the diffusion/dispersion, the advection and degradation mechanisms. The sorption mechanism is considered via the retardation factor, $R_{f}$ (dimensionless) which is calculated via the sediment porosity, $\varphi$, the sediment bulk density, $\rho_{b}$, and the sediments partition coefficient, $K_{D}$ (Eq.(2)).

$R_{f}=1+\rho_{b} k_{D} / \varphi$

Eq.(1) and Eq.(2) were solved by assuming the following initial and boundary conditions in Eq.(3) and Eq.(4):

\section{Initial conditions}

$$
\begin{array}{lrl}
\left.C(z, t)\right|_{t=0}=C_{0} & & 0 \leq z \leq h_{\text {sed }} \\
\left.C(z, t)\right|_{t=0}=0 & & h_{\text {sed }} \leq z \leq H
\end{array}
$$

\section{Boundary conditions}




$$
\begin{aligned}
& -\left.D_{b i o} \frac{d C(z, t)}{d z}\right|_{z=H}-\left.k_{b l} C(z, t)\right|_{z=H}=0 \\
& -\left.D_{c a p} \frac{d C(z, t)}{d z}\right|_{z=h_{b i o}}=-\left.D_{b i o} \frac{d C(z, t)}{d z}\right|_{z=h_{b i o}} \\
& -\left.D_{c a p} \frac{d C(z, t)}{d z}\right|_{z=h_{c a p}}=-\left.D_{e f f} \frac{d C(z, t)}{d z}\right|_{z=h_{c a p}} \\
& \left.\frac{d C(z, t)}{d z}\right|_{z=0}=0
\end{aligned}
$$

Where the subscripts bio, cap and sed denote parameters for the bioturbation and cap layer and sediments, respectively. The reference system was assumed to start at the bottom of the sediments and $H$ is the size of the domain in $z$-direction. As shown in Eq.(3) a uniformly contaminated sediment layer underneath the cap layer was considered and no contaminant was assumed in the cap. The boundary conditions in Eq.(4) show that a no flux condition was considered at the bottom of the contaminated sediments while the flux at the interface with the upper water was assumed as dependent on the parameter $k_{b l}$, which is the boundary layer mass transfer coefficient [19]. In addition a continuous flux through the layers was assumed but different dispersion coefficients were given in $h_{\text {sed }}, h_{c a p}$ and $h_{\text {bio }}$ equal respectively to $D_{\text {eff }}, D_{c a p}$ and $D_{\text {bio }}$.

The effective hydrodynamic dispersion $D_{\text {eff, }}$, in Eq.(1), was calculated as follows:

$D_{e f f}=D_{m} \varphi^{\frac{4}{3}}+\alpha_{D} w / \varphi$

where $D_{m}$ is the molecular diffusion coefficient while $\alpha_{D}$ is the dispersivity $(\mathrm{cm})$ into sediments. This latter was estimated via a power function, dependent on the cap thickness, $h_{c a p}[19]$ as in Eq.(6).

$\alpha_{D}=0.0169 h_{\text {cap }}^{1.53}$

The effective diffusivity of the cap system, $D_{c a p}$, was estimated as a sum of:

$D_{\text {cap }}=D_{\text {eff }}+\alpha_{D} w$

The diffusion mechanism in the bioturbation layer, $D_{\text {bio }}$, was estimated via Eq.(8), by taking into account both bioturbation and bioirrigation mechanisms modelled as local bio-diffusive processes [5, 19]:

$D_{\text {bio }}=D_{\text {cap }}+D_{\text {bio }}^{p w}+\lambda_{D} R_{f} D_{\text {bio }}^{p}$ 
In Eq.(8) $D_{\text {bio }}^{p w}$ and $D_{\text {bio }}^{p}$ are respectively the porewater bio-diffusion coefficient (i.e., for bioirrigation process) and the particle bio-diffusion coefficient (i.e., for bioturbation process).

The numerical solution of Eqs.(1)-(8) was obtained via COMSOL Multiphysics®, which uses finite element modelling. A predictive model of concentrations in bed sediments and overlying water was developed in order to evaluate the long term effectiveness of the ISC layer, allowing a determination of the vertical concentration profiles over time, with and without intervention.

\subsection{Case study}

The case study examined PCBs contaminated sediments of Lake Hartwell, an artificial lake located in the north-west region of South Carolina, USA. Lake Hartwell was created in 1955 by the U.S. Army Corps of Engineers (USACE) and covers nearly 22,660 ha of water with a shoreline of $1,500 \mathrm{~km}$. In the surrounding land there are numerous small towns, forests, and agricultural areas and the City of Clemson. It is classified as a Class A surface water, suitable for primary and secondary contact recreation (i.e. swimming, water-skiing, fishing, boating, etc), drinking water supply and agricultural/industrial use [33].

From 1955 to 1978, Lake Hartwell sediments were contaminated by PCBs released from the Sangamo-Weston, a capacitors manufacturing plant, located approximately $24 \mathrm{~km}$ upstream along Town Creek, which is a tributary of Twelvemile Creek (Fig.3). This plant used a variety of dielectric fluids in its manufacturing processes, which included fluids containing PCBs [33]. PCBs fall within the group of toxic and hazardous substances, whose adverse effects on living organisms can take effect even in relatively low concentrations. In addition, they are persistent organic pollutants with significant bioaccumulation potentials [34, 35].

For this reason, Lake Hartwell was placed on the National Priorities List in 1990. In particular the PCBs contamination was found in the Twelvemile Creek and the site was called "SangamoWeston/Twelvemile Creek/Lake Hartwell Superfund Site" [33]. The 1994 Record of Decision set a clean-up requirement of $1.0 \mathrm{mg} / \mathrm{kg}$ and it was assessed that two more preventive goals of 0.4 and $0.05 \mathrm{mg} / \mathrm{kg}$ total PCBs in near-surface sediment would be met in 2004 and 2023 [25, $33,36]$. The value of $0.05 \mathrm{mg} / \mathrm{kg}$ is representative of the more commonly reported background based sediment criteria for PCBs and equal to the effect range-low from NOAA (National Oceanic and Atmospheric Administration) based on an evaluation of published criteria associated with biological effects on aquatic life, and it was the limit set for this study. Similar values are in Europe, e.g. the Italian regulatory threshold limit for PCBs is set to $0.06 \mathrm{mg} / \mathrm{kg}$ for soils in residential areas like Lake Hartwell. In Canada instead, the recommended acceptable background concentration that applies to agricultural and residential/parkland land uses was defined as $0.3 \mathrm{mg} / \mathrm{kg}$ for total PCBs [37].

The current US EPA clean-up plan for the Twelvemile Creek watershed and portions of Lake Hartwell relies on natural attenuation, specifically the natural capping of contaminated sediment by the continued deposition of clean sediment [36] and annual monitoring of PCBs in sediment and aquatic biota has been conducted since 1995. Several studies illustrated the persistence and distribution of PCBs in the analysed site until recent years [34, 38]. Last sediment cores sampled from Lake Hartwell were collected in 2016 [38], shown in Fig.3. Total PCB concentrations were below $1 \mathrm{mg} / \mathrm{kg}$ at all sediment stations to a maximum of $0.911 \mathrm{mg} / \mathrm{kg}$ at Station SD-015, but all values were higher than the more restrictive goals of 0.4 and $0.05 \mathrm{mg} / \mathrm{kg}$. The PCBs concentration at station SD-015 was considered in the present study. 
Fig.3c shows the PCBs concentration trend of this station during the years and comparison with the background Total PCBs value limit set at $0.05 \mathrm{mg} / \mathrm{kg}$.
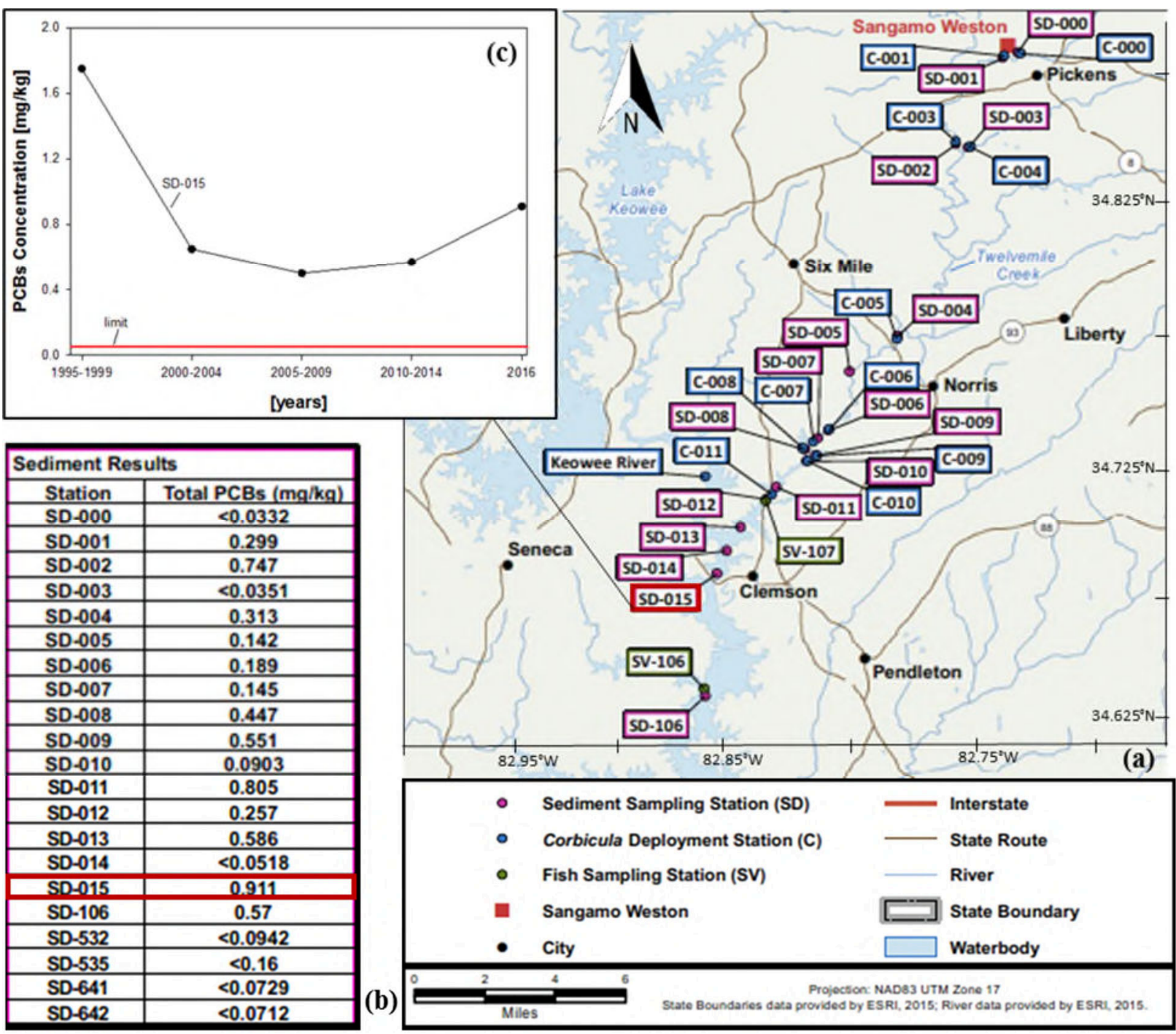

\begin{tabular}{|c|c|}
\hline \multicolumn{2}{|l|}{ Sediment Results } \\
\hline Station & Total PCBs (mq/kg) \\
\hline SD-000 & $<0.0332$ \\
\hline SD-001 & 0.299 \\
\hline SD-002 & 0.747 \\
\hline SD-003 & $<0.0351$ \\
\hline SD-004 & 0.313 \\
\hline SD-005 & 0.142 \\
\hline SD-006 & 0.189 \\
\hline SD-007 & 0.145 \\
\hline SD-008 & 0.447 \\
\hline SD-009 & 0.551 \\
\hline SD-010 & 0.0903 \\
\hline SD-011 & 0.805 \\
\hline SD-012 & 0.257 \\
\hline SD-013 & 0.586 \\
\hline SD-014 & $<0.0518$ \\
\hline SD-015 & 0.911 \\
\hline SD-106 & 0.57 \\
\hline SD-532 & $<0.0942$ \\
\hline SD-535 & $<0.16$ \\
\hline SD-641 & $<0.0729$ \\
\hline SD-642 & $<0.0712$ \\
\hline & \\
\hline & 0.0 \\
\hline
\end{tabular}

Fig 3. PCB sediment concentration measurements of 2016 in Lake Hartwell and their localizations. (a) Localization stations of measurement (b) Total PCBs concentrations measured; (c) Station SD-015 Total PCBs concentrations trend over time. [38]

In COMSOL the effect of diffusion, adsorption, biodegradation reactions and the effect of the burrowing activity of the benthic fauna into sediments (bioturbation) were considered [19].

The model input parameters for the case study are listed in Table 1.

Site specific parameter values for the contaminant's theoretical diffusivity in water, particle density, porosity, sedimentation rate, degradation and benthic boundary layer mass transfer coefficient were collected from previous studies [25, 26, 36, 38] and/or assessed a priori. The molecular diffusivity of PCB in water, $D_{m}$, was set equal to $10^{-7} \mathrm{~cm}^{2} / \mathrm{s}$ [26].

Station SD-015 is located between the US123 Bridge and the Hwy 93 Bridge (Fig.3), for which, the 1994 Record of Decision [33] estimated a low sediment burial rate (w), ranging from 0 and 
$1 \mathrm{~cm} /$ year and no significant erosion was observed in the area. Consequently a sedimentation rate, $w$, equal to $1 \mathrm{~cm} /$ year was considered.

Table 1. Input parameters

\begin{tabular}{lcc}
\hline Sediments and cap properties & unit & \\
\hline Porosity, $\varphi$ & {$[-]$} & 0.5 \\
Organic carbon fraction, $f_{o c}$ & {$[-]$} & $0.0011-0.036$ \\
Sedimentation rate, $w$ & {$[\mathrm{~cm} / \mathrm{y}]$} & 1 \\
Effective hydrodynamic Dispersion, $D_{\text {eff }}$ & {$\left[\mathrm{cm}^{2} / \mathrm{s}\right]$} & $7.9410^{-7}$ \\
Molecular PCBs Diffusion, $D_{m}$ & {$\left[\mathrm{~cm}^{2} / \mathrm{s}\right]$} & $110^{-7}$ \\
Sediment bulk density, $\rho$ B & {$[\mathrm{kg} / \mathrm{l}]$} & 2.6 \\
Degradation rate, $\lambda_{r}$ & {$[1 / \mathrm{year}]$} & 0.013 \\
PCBs initial concentration, $C_{0}$ & {$[\mathrm{mg} / \mathrm{kg}]$} & 0.911 \\
Sand cap thickness, $h_{\text {cap }}$ & {$[\mathrm{cm}]$} & 23.4 \\
Bioturbation layer thickness, $h_{b i o}$ & {$[\mathrm{~cm}]$} & 10 \\
Pore water biodiffusion coefficient $D_{\text {bio }}^{p w}$, & {$[\mathrm{cm} / \mathrm{s}]$} & 10.5 \\
Particle biodiffusion coefficient $D_{\text {bio }}^{p}$, & {$[\mathrm{cm} / \mathrm{s}]$} & 10.7 \\
Boundary layer mass transfer coefficient, $k_{b l}$ & {$[\mathrm{~cm} / \mathrm{h}]$} & 10 \\
\hline
\end{tabular}

The degradation rate constant $\lambda_{r}$ was obtained from $[39,40]$ where it was reported that the average dechlorination rate of Twert Creek is $6.9 \times 10^{-6} \mathrm{~mol}$ of $\mathrm{Cl} / \mathrm{g}$ of $\mathrm{PCB} /$ week.

Because pore-water aqueous-phase concentrations were not measured at Lake Hartwell, they were estimated using Eq.(9), :

$C_{w}=C_{s} / K_{D}=C_{s} / K_{o c} f_{o c}$

where $C_{w}$ is the aqueous-phase $\mathrm{PCB}$ concentration $(\mathrm{kgPCB} / \mathrm{L}), C_{s}$ is the solid-phase concentration ( $\mathrm{mg}$ of $\mathrm{PCB} / \mathrm{kg}$ of sediment), $\mathrm{K}_{\mathrm{D}}(\mathrm{L} / \mathrm{kg})$ is the sediment/porewater equilibrium coefficient, $K_{o c}(\mathrm{~L} / \mathrm{kg})$ is the organic carbon equilibrium coefficient, and $f_{o c}$ is the fraction of organic carbon. Eq.(9) is a widely accepted model for sorption of hydrophobic organic compounds (HOC) onto sediments [41], where $K_{D}$ is a constant and related to $K_{o c}$.

Sediments in the creek are recorded as being composed primarily of sand and have a total organic carbon content $\left(f_{o c}\right)$ ranging from 0.11 and 3.6 percent [38]. For this reason, two scenarios ( $S C 1$ and $S C 2$ ) were considered and a comparison with sand cap design with different sorption characteristics was developed. In addition, it was assumed a $\log K_{o c}$ equal to 4.3, consistent with Zwiernik's calculations [25].

The corresponding $K_{D}$ and $R_{f}$ obtained from Eq.(9) and (2) are reported in Table 2.

Table 2. Values for $S C 1$ and $S C 2$

\begin{tabular}{lcc}
\hline & $\boldsymbol{S C 1 : K _ { \boldsymbol { D } } \boldsymbol { 1 }}$ & $\boldsymbol{S C 2}: \boldsymbol{K}_{\boldsymbol{D}} \boldsymbol{2}$ \\
\hline$f_{o c}[-]$ & 0.0011 & 0.036 \\
$K_{D}[\mathrm{~L} / \mathrm{kg}]$ & 21.95 & 718.3 \\
$R_{f}[-]$ & 115 & 3,736 \\
\hline
\end{tabular}




\section{RESULTS AND DISCUSSION}

The sediment capping system was modelled with four layers, including the overlying water column, the sediment cap (further divided into a biologically active layer, also known as the bioturbation layer, $h_{b i o}$, and the effective cap layer, $\left.h_{\text {cap }}\right)$, and the contaminated sediment bed, $h_{\text {sed }}$, as represented in Fig.2.

Sand cap layers of increasing thicknesses were simulated for both scenarios $S C 1$ and $S C 2$, and the Total PCBs concentrations obtained at the cap/water interface over time with and without intervention were compared with the background Total PCBs value limit set at $0.05 \mathrm{mg} / \mathrm{kg}$ (represented with a red solid line). Biological degradation was considered in both sediment and overlying cap. In addition, the $h_{\text {cap }}$ thicknesses were incremented of $10 \mathrm{~cm}$ up to $50 \mathrm{~cm}$, while the biologically active layer (i.e., bioturbation layer), $h_{b i o}$, was assumed to be $10 \mathrm{~cm}$ deep measured from the sediment-water interface. A reasonable value for $k_{b l}$ was $10 \mathrm{~cm} / \mathrm{h}[16,19$, 30].

In COMSOL Multiphysics, the bioreactive transport of PCBs through the sand cap layers was simulated using Eqs.(1)-(9) where $D_{\text {eff }}$ was modelled as discontinuous functions at depths $h_{\text {cap }}$ and $h_{\text {bio }}$ respectively, as shown in Eq.(5). The effective cap layer Dispersion coefficient, $D_{c a p}$, the bioturbation layer Dispersion coefficient, $D_{b i o}$ the Dispersivity, $\alpha_{D}$ were calculated via the equations in Section 2.1 (Eq.(2) and Eqs.(6)-(8)) and results are listed in Table 3.

Table 3. Input parameters for both scenarios $S C 1$ and $S C 2$

\begin{tabular}{llcccc}
\hline & & \multirow{2}{*}{$\boldsymbol{\alpha}[\mathrm{cm}]$} & $\boldsymbol{D}_{\text {cap }}\left[\mathrm{cm}^{2} / \mathrm{s}\right]$ & \multicolumn{2}{c}{$\boldsymbol{D}_{\text {bio }}\left[\mathrm{cm}^{2} / \mathrm{s}\right]$} \\
& & & & $\boldsymbol{S C 1}: \boldsymbol{K}_{\boldsymbol{D} 1}$ & $\boldsymbol{S C 2 : K \boldsymbol { D } \boldsymbol { Z }}$ \\
\hline 1 & no cap & - & $7.9410^{-7}$ & $1.7710^{-5}$ & $2.3410^{-4}$ \\
2 & $h_{\text {cap }}=10 \mathrm{~cm}$ & 0.07 & $7.9710^{-7}$ & $1.7710^{-5}$ & $2.3410^{-4}$ \\
3 & $h_{\text {cap }}=20 \mathrm{~cm}$ & 0.19 & $8.0310^{-7}$ & $1.7710^{-5}$ & $2.3410^{-4}$ \\
4 & $h_{\text {cap }}=30 \mathrm{~cm}$ & 0.35 & $8.1010^{-7}$ & $1.7710^{-5}$ & $2.3410^{-4}$ \\
5 & $h_{\text {cap }}=40 \mathrm{~cm}$ & 0.55 & $8.2010^{-7}$ & $1.7710^{-5}$ & $2.3510^{-4}$ \\
6 & $h_{\text {cap }}=50 \mathrm{~cm}$ & 0.77 & $8.3010^{-7}$ & $1.7710^{-5}$ & $2.3510^{-4}$ \\
\hline
\end{tabular}

Results of simulations are shown in Fig.4-6, and normalised Total PCBs concentrations are reported. In particular results were represented for cap thicknesses $h_{\text {cap }}$ equal respectively to 10 $\mathrm{cm}$ (corresponding to $h_{b i o}$ ), $30 \mathrm{~cm}$ and $50 \mathrm{~cm}$ for both scenario $S C 1$ (Fig.4) and SC2 (Fig.5).

Fig. 4 and 5 show the normalised Total PCBs concentration profiles vs sediments depth over simulation time of respectively 10, 30 and 100 years, compared with the limit, respectively for SC1 (Fig.4) and SC2 (Fig.5).

Fig.6, instead, represents the concentration at the cap/water interface by increasing the sediment cap and comparing that with no intervention (no cap). 
a) $S C 1: h_{\text {cap }}=10 \mathrm{~cm}$
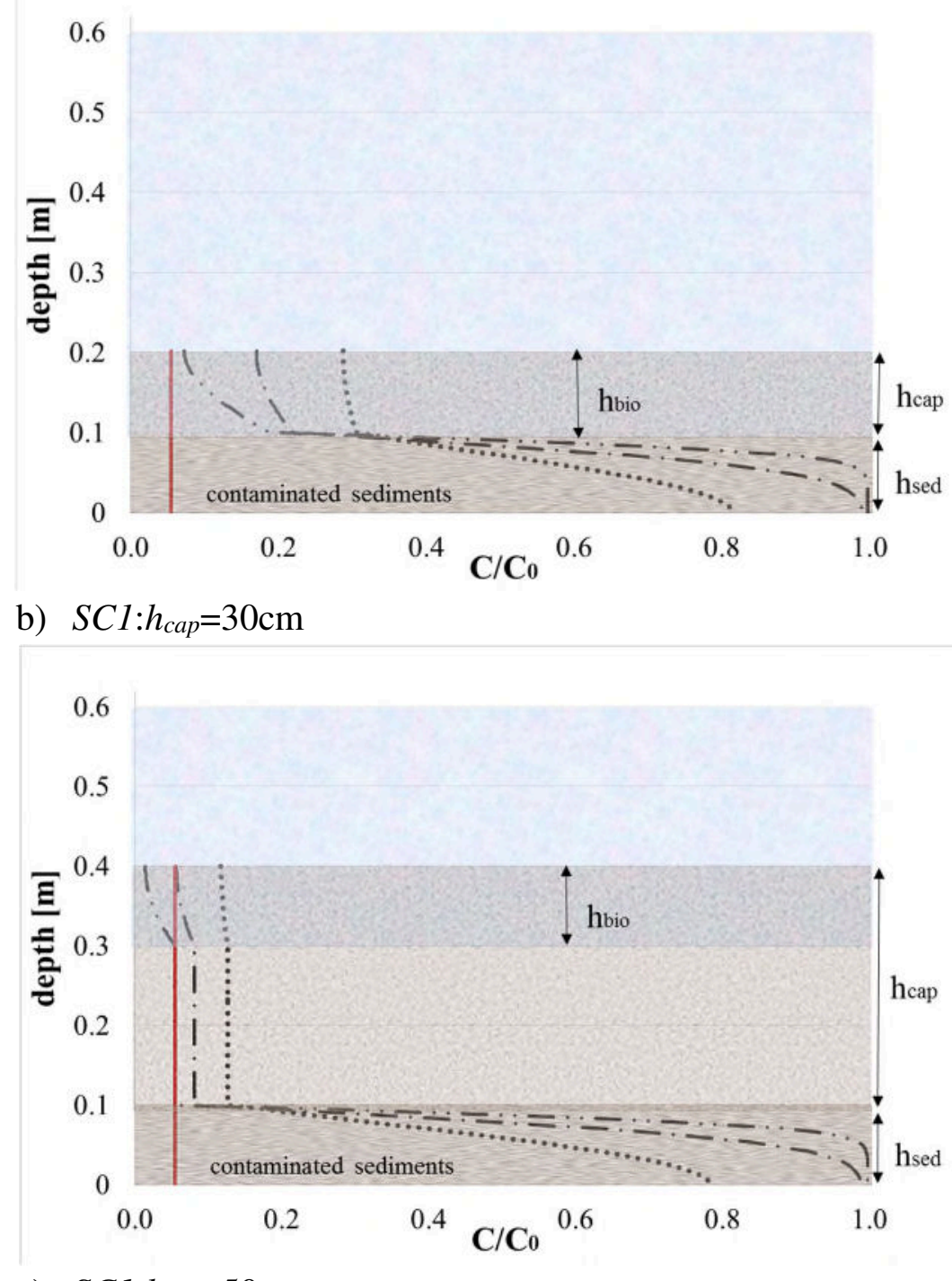

c) $S C 1: h_{\text {cap }}=50 \mathrm{~cm}$

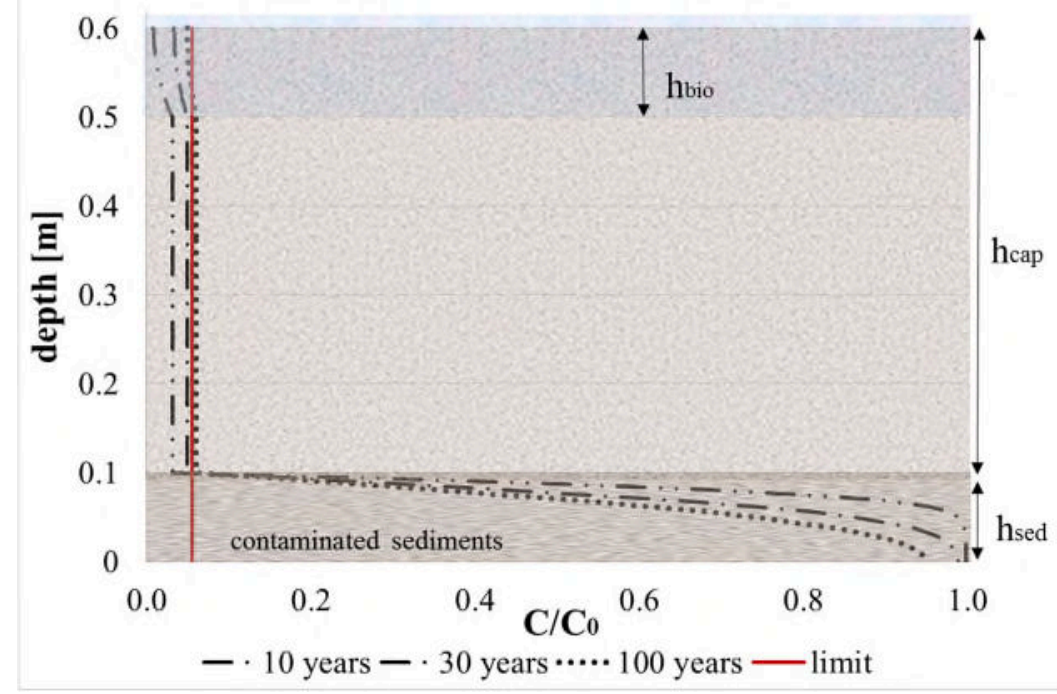

Fig 4. Total PCB concentration -depth profiles for Scenario 1 for a capping thickness respectively of a) $h_{c a p}=10 \mathrm{~cm} \mathrm{b)} h_{c a p}=30 \mathrm{~cm}$ and c) $h_{c a p}=50 \mathrm{~cm}$. 
a) $S C 2: h_{\text {cap }}=10 \mathrm{~cm}$
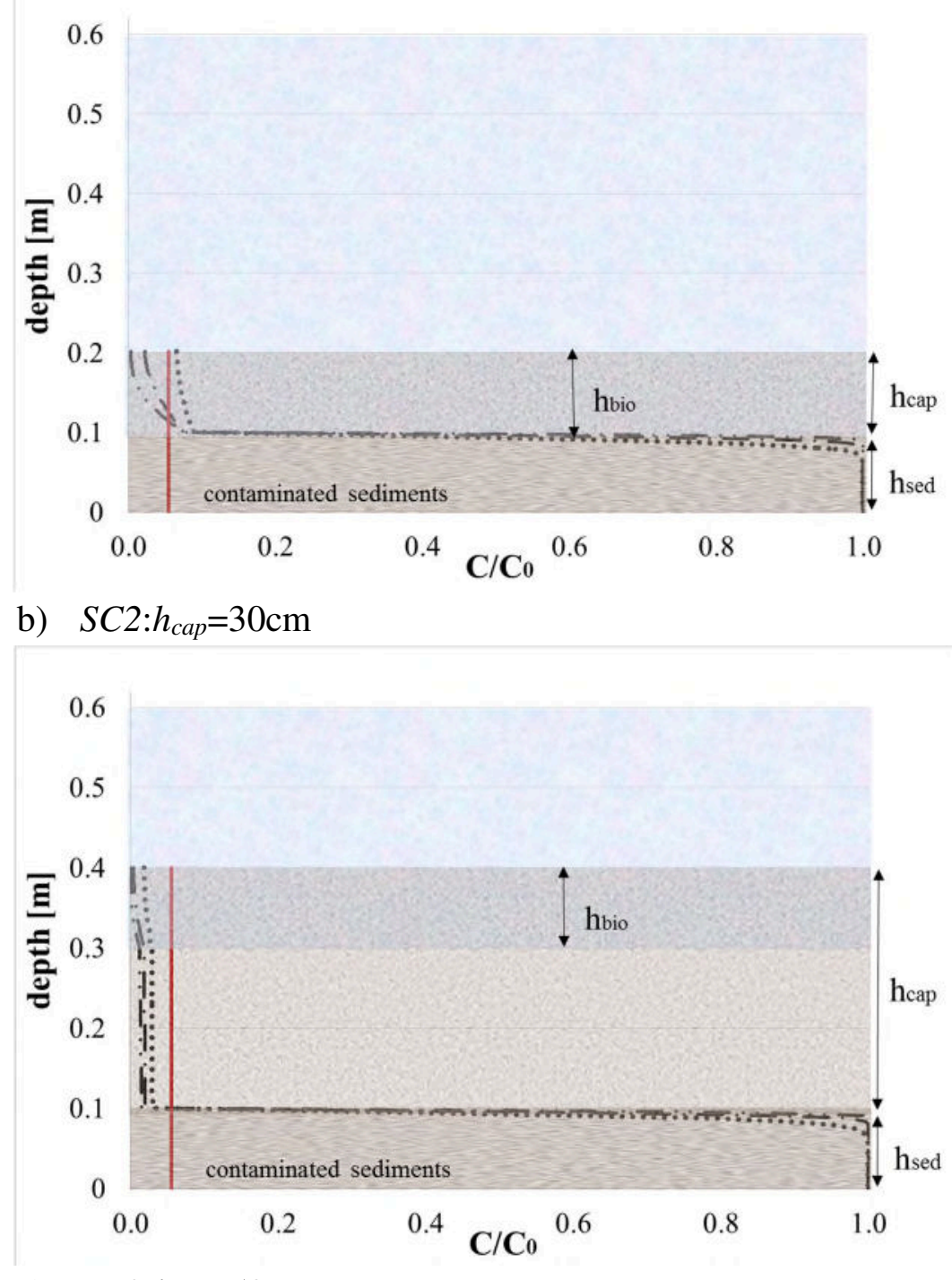

c) $S C 2: h_{\text {cap }}=50 \mathrm{~cm}$

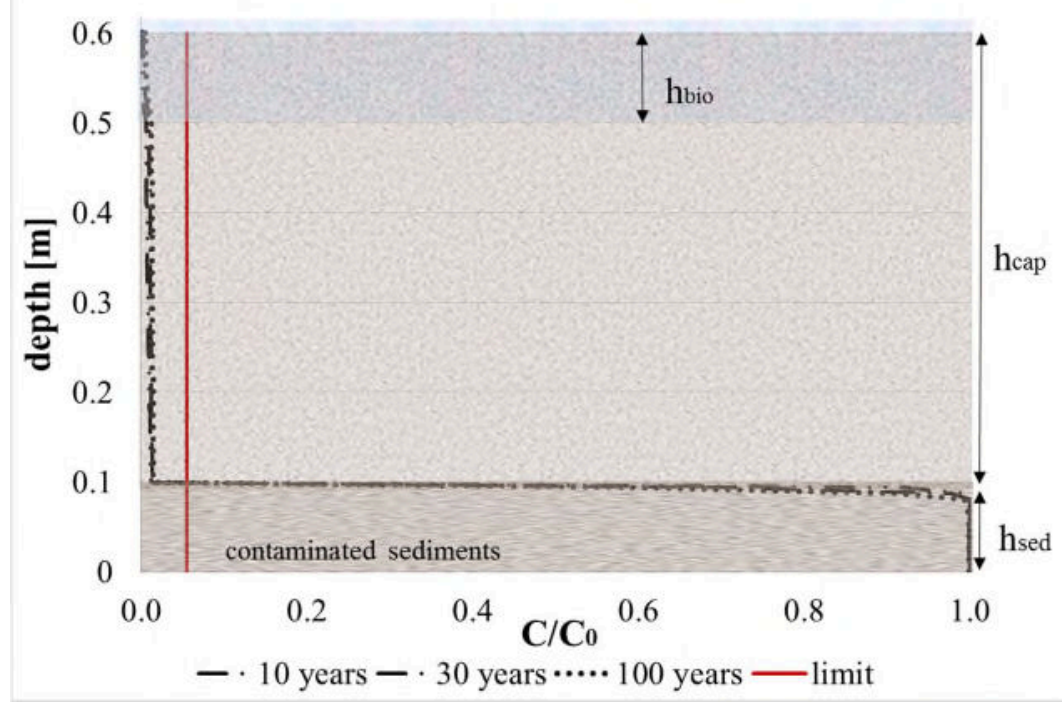

Fig 5. Total PCB concentration -depth profiles for Scenario 2 for a capping thickness respectively of a) $h_{c a p}=10 \mathrm{~cm} \mathrm{b)} h_{c a p}=30 \mathrm{~cm}$ and c) $h_{c a p}=50 \mathrm{~cm}$. 
a) SC1: $K_{D} 1$

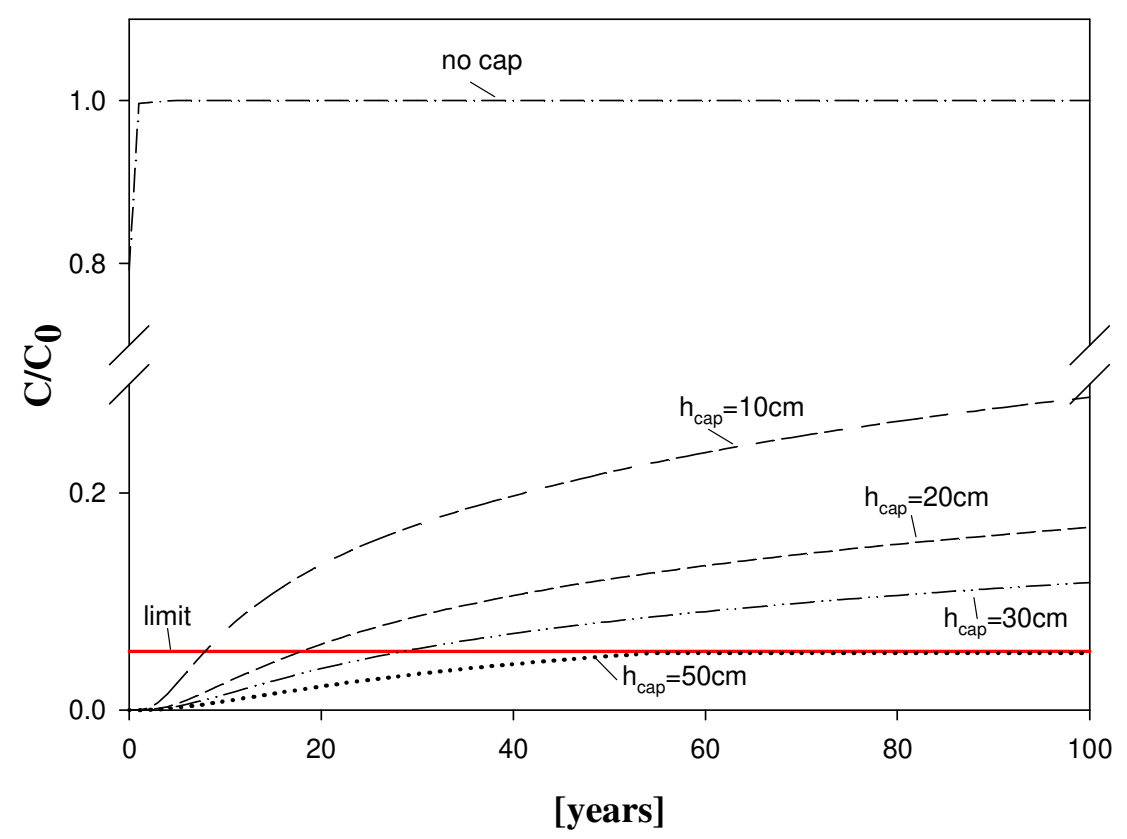

b) $S C 2: K_{D} 2$

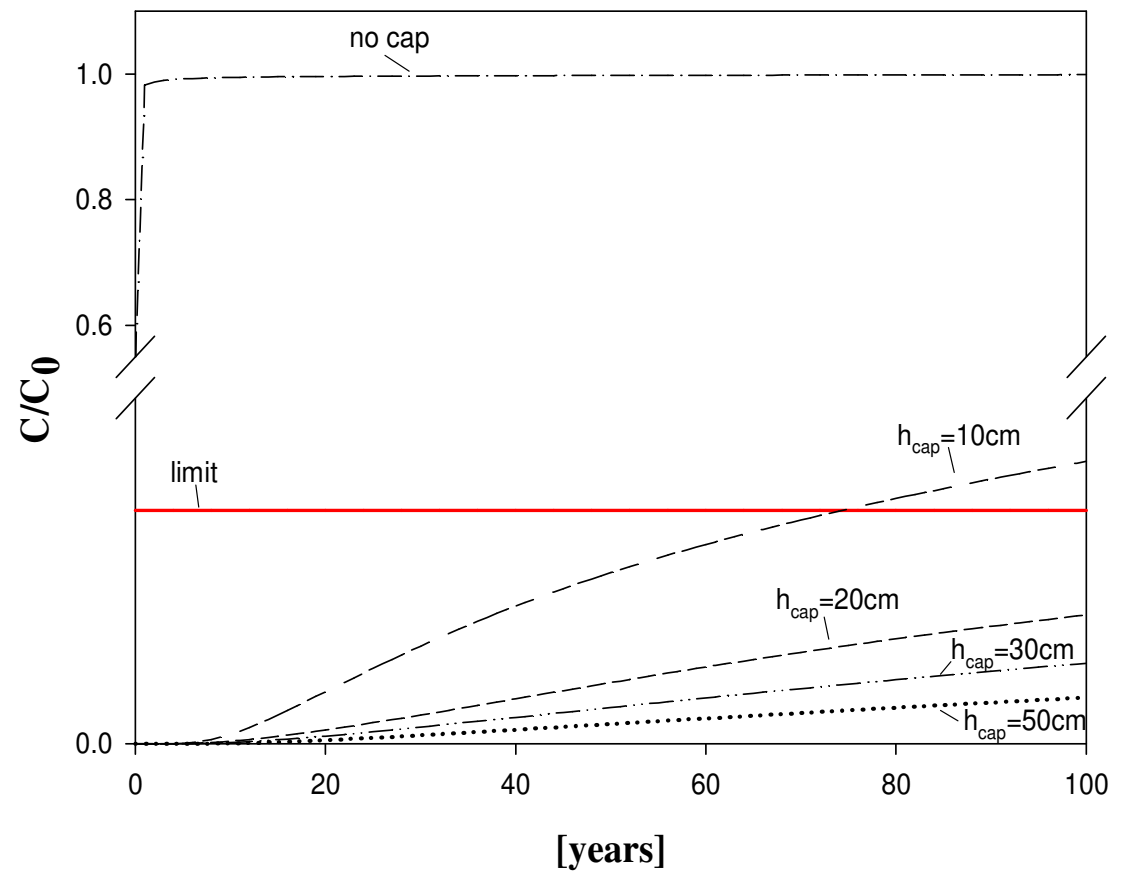

Fig 6. Total PCBs normalised concentration over time at the sediment capping- water interface, by increasing the sand cap thickness, respectively for $S C 1$ (a) and $S C 2$ (b), at point SD-015 in Lake Hartwell, SC, USA.

As shown by increasing the cap thickness, PCBs concentrations are efficiently reduced and at any run time the PCBs concentration at the cap-water interface are always lower than the limit set at $0.05 \mathrm{mg} / \mathrm{kg}$.

The different sand cap thicknesses allow the clean-up goal to be reached over time for both scenarios. In particular, for $S C 1$ it is required a $h_{\text {cap }}$ of 50 while it is only of $20 \mathrm{~cm}$ for $S C 2$. This 
is because of the low sand sorption characteristics of $S C 1$. This confirms the high effect that the sediment-water partitioning coefficients have on the concentrations released in the water pores. Previous studies showed that natural or added strong sorbents in sediments reduce the availability of PCBs or PAHs to earthworms [42, 43], without showing adverse effects of sediment amendment. Consequently it is evident that by increasing the sorbent properties of cap materials it is possible to further reduce PCBs transport into sediment and upper water layer, for small cap thicknesses.

\section{Conclusions}

This study deals with a sand cap design for contaminated sediments, proposed as an in-situ remediation technology to minimize the exposure of aquatic ecosystems to contamination. PCBs contaminated sediments of Lake Hartwell, an artificial lake located in the north-west region of South Carolina, USA, were examined as case study. Numerical simulations were performed via COMSOL Multiphysics $®$ and looked at two different scenarios, by considering site specific biodegradation rate within the cap and comparing sand caps with low $(S C 1)$ and high ( $S C 2$ ) sorption characteristics at different cap thicknesses.

Results showed that a sand cap, properly dimensioned, can be an effective remedial strategy for contaminated sediments. For both scenarios analysed, PCBs concentrations at the overlying water interface were reduced and isolated for the simulated period both from the bioactive zone and from the above water layer. It was shown that PCBs transport was highly influenced by the cap material sorption characteristics, and that the use of material with high sorbent properties can further reduce the cap thickness. Future work will test the use of an in-situ multilayered adsorptive capping (ISAC), by adding activated carbon with application in shallow waters.

\section{Acknowledgments}

We thank Mr. Craig Zeller (U.S.EPA, GA) for his collaboration and availability in sharing the Lake Hartwell, Sangamo-Weston/Twelvemile Creek/Lake Hartwell Superfund Site recent data.

\section{List of symbols}

$\begin{array}{ll}C & \text { Liquid concentration, } \mu \mathrm{g} \mathrm{L}^{-1} \\ C_{o} & \text { Initial pollutant concentration, } \mathrm{mg} \mathrm{kg}^{-1} \\ C_{s} & \text { Solid phase pollutant concentration, } \mathrm{mg} \mathrm{kg}^{-1} \\ \mathrm{C}_{\mathrm{w}} & \text { Aqueous-phase contaminant concentration, } \mu \mathrm{g} \mathrm{\textrm {L } ^ { - 1 }} \\ D_{\text {eff }} & \text { Hydrodynamic dispersion coefficient, } \mathrm{cm}^{2} \mathrm{~s}^{-1} \\ D_{\text {cap }} & \text { Effective cap layer diffusivity/dispersivity, } \mathrm{m}\end{array}$




\begin{tabular}{|c|c|}
\hline$D_{m}$ & Molecular contaminant diffusion, $\mathrm{cm}^{2} \mathrm{~s}^{-1}$ \\
\hline$D_{b i o}^{p}$ & Particle biodiffusion coefficient, $\mathrm{cm}^{2} \mathrm{~s}^{-1}$ \\
\hline$D_{\text {bio }}^{p w}$ & Pore water biodiffusion coefficient, $\mathrm{cm}^{2} \mathrm{~s}^{-1}$ \\
\hline$f_{o c}$ & Organic carbon fraction \\
\hline$H$ & Extension domain in $\mathrm{z}$ direction \\
\hline$h_{\text {bio }}$ & Bioturbation layer thickness, $\mathrm{cm}$ \\
\hline$h_{\text {cap }}$ & Cap thickness, cm \\
\hline$h_{\text {sed }}$ & Contaminated sediments depth, $\mathrm{cm}$ \\
\hline$k_{b l}$ & Boundary layer mass transfer coefficient, $\mathrm{cm} \mathrm{h}^{-1}$ \\
\hline$K_{O C}$ & Organic carbon equilibrium coefficient, L kg-1 \\
\hline$K_{D}$ & Partitioning coefficient, $\mathrm{L} \mathrm{kg}^{-1}$ \\
\hline$R_{f}$ & Retardation factor, - \\
\hline$t$ & Time, yr \\
\hline$w$ & Sedimentation rate, $\mathrm{cm} \mathrm{yr}^{-1}$ \\
\hline$\alpha_{D}$ & Sediments dispersivity, $\mathrm{cm}$ \\
\hline$\varphi$ & Sediments porosity, - \\
\hline$\lambda_{\mathrm{r}}$ & Degradation rate, $\mathrm{yr}^{-1}$ \\
\hline$\rho_{b}$ & Sediments bulk density, $\mathrm{kg} \mathrm{L}^{-1}$ \\
\hline
\end{tabular}

\section{References}

1. P.M. Chapman, F. Wang. Assessing sediment contamination in estuaries. Environ. Toxicol. Chem., 20 (2001) 3-22.

2. D. Barcelo, M. Petrovic. Sediment Quality and Impact Assessment of Pollutants. Elsevier, 2007.

3. L.J. Thibodeaux, K.T. Valsaraj and D.D. Reible. Bioturbation driven transport of hydrophobic organic contaminants from bed sediment. Environ. Eng. Sci. 18 (2001) 215223.

4. US Environmental Protection Agency (USEPA). Contaminated Sediment Remediation Guidance for Hazardous Waste Sites. EPA 540-R-05-012. 2005. 
5. F.J.R. Meysman, B.P. Boudreau, J.J. Middelburg. Modeling reactive transport in sediments subject to bioturbation and compaction. Geochim. Cosmochim. Ac., 69 (2005) 3601-3617.

6. D. D. Reible. Processes, Assessment and Remediation of Contaminated Sediments. Springer Science \& Business Media, 2014.

7. S.E. Apitz, J.W. Davis, K. Finkelstein, D.W. Hohreiter, R. Hoke,; R.H. Jensen, J. Jersak, V.J. Kirtay, E.E. Mack, V.S. Magar, D.D. Reible, R.G. Stahl. Assessing and Managing Contaminated Sediments: Part II, Evaluating Risk and Monitoring Sediment Remedy Effectiveness. Integr. Environ. Assess. Managem., 1 (2005) 1-14.

8. National Research Council (NRC). Contaminated Sediments in Ports and Waterways: Cleanup Strategies and Technologies. Washington, DC: The National Academies Press. 1997. https://doi.org/10.17226/5292.

9. K.E. Gustavson, G.A. Burton, N.R. Francinques, D.D. Reible, D.J. Vorhees, J.R. Wolfe. Evaluating the effectiveness of contaminated sediment dredging. Environ. Sci. Tech., 42 (2008) 5042-5047.

10. M. Palermo, S. Maynord, J., Miller, D.D. Reible. Guidance for in situ subaqueous capping of contaminated sediments EPA 905-B96-004. 1998.

11. G.F. Santonastaso, A. Erto, I. Bortone, S. Chianese, A. Di Nardo, D. Musmarra. Experimental and simulation study of the restoration of a thallium (I)-contaminated aquifer by Permeable Adsorptive Barriers (PABs). Sci. Tot. Environ., 63 (2018) 62-71.

12. I. Bortone, A. Erto, G. Santonastaso, A. Di Nardo, M. Di Natale, D. Musmarra. Design of Permeable Adsorbing Barriers (PABs) for groundwater remediation by COMSOL Multiphysics simulations. Desal. Water Treat., 55 (2015) 3231-3240.

13. A. Erto, A. Lancia, I. Bortone, A. Di Nardo, M. Di Natale, D. Musmarra. A procedure to design a Permeable Adsorptive Barrier (PAB) for contaminated groundwater remediation. J. Environ. Manag., 92 (2001) 23-30.

14. X. Q. Wang; L. J. Thibodeaux; K. T. Valsaraj, D. D. Reible. Efficiency of capping contaminated bed sediments in situ. 1. Laboratory scale experiments on diffusionadsorption in the capping layer. Environ. Sci. Technol., 25 (1991) 1578-1584.

15. G. S. Samuelsson, C. Raymond, S. Agrenius, M. Schaanning, G. Cornelissen, J. S. Gunnarsson. Response of marine benthic fauna to thin-layer capping with activated carbon in a large-scale field experiment in the Grenland fjords, Norway. Environ. Sci. Pollut. Res. Int., 24 (2017) 14218-14233.

16. D. D. Reible, C., Kiehl-Simpson, A. Marquette. Modelling chemical fate and transport in sediment caps. Technical Presentation 380-D, American Institute of Chemical Engineers, N.Y. 2004.

17. G. J. Thoma, D. D. Reible, K. T. Valsara, L. J. Thibodeaux. Efficiency of capping contaminated bed sediments in situ. 2. Mathematics of diffusion-adsorption in the capping layer. Environ. Sel. Technol., 27 (1993) 2412-2419.

18. D. J. Lampert, D. D. Reible. An analytical modeling approach for evaluation of capping of contaminated sediments. Soil Sed. Contam., 18 (2009) 470-488.

19. J. Go, D. J. Lampert, J. A. Stagemann, D. Reible. Prediction contaminant fate and transport in sediment caps: Mathematical modeling approaches. Appl. Geochem., 24 (2009) 13471353.

20. B. A. Bessinger, D.Vlassopoulos, S. Serrano, P. A. O’Day. Reactive Transport Modeling of Subaqueous Sediment Caps and Implications for the Long-Term Fate of Arsenic, Mercury, and Methylmercury. Aqua. Geochem., 18 (2012) 297-326.

21. P. Z. Viana, K. Yin. Modeling Active Capping Efficacy. 1. Metal and Organometal Contaminated Sediment Remediation. Environ. Sci. Techno., 42 (2008) 8922- 8929. 
22. S. S. Sengor, N.F. Spycher, T.R. Ginn, R.K. Sani, B. Peyton. Biogeochemical reactivediffusive transport of heavy metals in Lake Coeur d'Alene sediments. Appl. Geochem., 22 (2007) 2569-2594.

23. C. A. Goring. Control of nitrification by 2-chloro-6-(trichloro-methyl) pyridine. Soil Sci., 93 (1962) 211-218.

24. R. Schwarzenbach, P.M. Gschwend, D.M. Imboden. Environmental Organic Chemistry, 2nd ed. Wiley-Interscience, Hoboken, NJ, USA. 2003.

25. R.C. Brenner, V.S. Magar, J.A. Ickes, E.A. Foote, J.E. Abbott, L.S. Bingler, E.A. Crecelius. Long-Term Recovery of PCB-Contaminated Surface Sediments at the Sangamo-Weston/Twelvemile Creek/Lake Hartwell Superfund Site. Environ. Sci. Technol., 38 (2004) 2328-2337.

26. V.S. Magar, G. Johnson, R.C. Brenner, J.F. Quensen III, E.A. Foote, G. Durell, J.A. Ickes, C. Peven-McCarthy Long-term recovery of PCB-contaminated sediments at the Lake Hartwell Superfund Site: PCB dechlorination I-End member characterization. Environ. Sci. Technol., 39 (2005) 3548-3554.

27. H. Wu, C. Lai, G. Zeng, J. Liang, J. Chen, J. Xu, J. Dai, X. Li, J. Liu, M. Chen, L. Lu, L. $\mathrm{Hu}, \mathrm{J}$. Wan. The interactions of composting and biochar and their implications for soil amendment and pollution remediation: a review. Crit. Rev. Biotechnol., 37 (2017) 754764.

28. G. Zeng, H. Wu, J. Liang, S. Guo, L. Huang, P. Xu, Y. Liu, Y. Yuan, X. He, Y. He. Efficiency of biochar and compost (or composting) combined amendments for reducing $\mathrm{Cd}, \mathrm{Cu}, \mathrm{Zn}$ and $\mathrm{Pb}$ bioavailability, mobility and ecological risk in wetland soil. RSC Advan., 5 (2015) 34541-34548.

29. B.W. Gu, C.G. Lee, T.G. Lee, S.J. Park. Evaluation of sediment capping with activated carbon and nonwoven fabric mat to interrupt nutrient release from lake sediments. Sci. Tot. Environ., 599-600 (2017) 413-421.

30. P. Murphy, A. Marquette, D. Reible, P.E. M. Asce, G. V. Lowry, M. Asce. Predicting the Performance of Activated Carbon-, Coke-, and Soil-Amended Thin Layer Sediment Caps. J. Environ. Eng., 132 (2006) 787-794.

31. R.K. Mohan, M.P. Brown, C.R. Barnes. Design criteria and theoretical basis for capping contaminated marine sediments. Appl. Oc. Research. 22 (2000) 85-93.

32. Y. Bachmat, J. Bear, Macroscopic modelling of transport phenomena in porous media. 1: The continuum approach. Transport Porous Med., 1 (1986) 213-240.

33. US Environmental Protection Agency (USEPA). Superfund Record of Decision:SangamoWeston/Twelvemile Creek/Lake Hartwell Site, Pickens, SC: Operable Unit 2 EPA/ROD/RO4-94/178. 1994.

34. F.M. Dunnivant, A.L. Polansky, A.W. Elzerman. Persistence and distribution of PCBs in the sediments of a reservoir (Lake Hartwell, South Carolina). B. Environ. Contam. Tox., 43 (1989) 870-878.

35. W.R. Abraham, B. Nogales, P.N. Golyshin, D.H. Pieper, K.N. Timmis, Polychlorinated biphenyl-degrading microbial communities in soils and sediments. Curr. Micobiol., 5 (2002), 246-253.

36. US Environmental Protection Agency (USEPA). The incidence and severity of sediment contamination in surface waters of the United States, national sediment quality survey. 2nd ed. Washington DC: Office of Science and Technology, Standards and Health Protection Division. EPA/823/R/04/007. 2004.

37. Ontario Ministry of Environment and Energy (OMEE). Ontario typical range of chemical parameters in soil, moss bags and snow. Version 1.0a. PIBS 2792. Standards Development Branch, Phytotoxicology Section, Toronto. 1993. 
38. CH2M HILL Engineers, Inc. (CH2M). Lake Hartwell 2016 Fish and Sediment Study, Sangamo Weston/Twelvemile Creek/Lake Hartwell PCB Contamination Superfund Site, Pickens County, South Carolina. Schlumberger Technology Corporation. 2016.

39. V.S. Magar, R.C. Brenner, G. Johnson, J.F. Quensen. III. Long-term recovery of PCBcontaminated sediments at the Lake Hartwell Superfund Site: PCB dechlorination IIRates and extent. Environ. Sci. Technol., 39 (2005) 3538-3547.

40. U. Pakdeesusuk, D. L. Freedman, C. M. Lee, J. T. Coates. Reductive dechlorination of polychlorinated biphenyls in sediment from the Twelve Mile Creek Arm of Lake Hartwell. Environ. Toxicol. Chem., 22 (2003) 1214-1220.

41. S. Karickhoff, D. Brown, T. Scott. Sorption of hydrophobic pollutants on natural sediments. Water Res., 13(1979) 241-248.

42. D. Werner, U. Ghosh, R.G. Luthy. Modeling Polychlorinated Biphenyl Mass Transfer after Amendment of Contaminated Sediment with Activated Carbon. Environ. Sci. Technol., 40 (2006) 4211-4218.

43. S. Josefsson, M. Schaanning, G.S. Samuelsson, J.S. Gunnarsson, I. Olofsson, E. Eek, K. Wiberg. Capping efficiency of various carbonaceous and mineral materials for in situ remediation of polychlorinated dibenzo-p-dioxin and dibenzofuran contaminated marine sediments: Sediment-to-water fluxes and bioaccumulation in boxcosm tests. Environ. Sci. Technol., 46 (2012) 3343-3351. 